\title{
VRIT: An Innovative Approach of Industrial Training through Virtual Reality
}

\author{
Mrs. D. Glory Ratna Mary ${ }^{1}$, Dr. E.Kirubakaran ${ }^{2}$ \\ ${ }^{\text {I}}$ (Computer Science Department, Women's Christian College, Nagercoil,India) \\ ${ }_{2}^{2}$ (Additional General Manager, Bharat Heavy Electricals Limited, Trichy,India)
}

\begin{abstract}
The emerging global competition and increasing costs are a great challenge to industries. New cost effective training methods are explored to cope with this demand. In-depth knowledge of the functions in a factory is of vital importance for greater safety and better efficiency. Desktop and web-based e-learning applications offer industrialists new tools to raise maintenance-related knowledge and competence. Simulated learning through virtual 3D animations let employees comprehend the internal mechanisms of the equipment and the co-relation between the different parts. The evolution of Web technologies in recent years has enabled the use of Virtual Reality (VR) modelling for visualization of manufacturing processes creating a Virtual Environment (VE). The VR modelling language (VRML), which has become the standard for transmitting $3 D$ virtual worlds across the Internet, can be used to control, interact and monitor manufacturing processes visually thus imparting training from a desktop computer. This paper deals with the simulation of the production of steel beams and columns presented to the subcontractors from a parent company.
\end{abstract}

Keywords - 3D animations, interactivity, Simulated Learning, Virtual Environment,VRML.

\section{Introduction}

Modeling is used to build structures that serve as proxies for other objects. Traditionally construction process information is communicated with paper documents and 2D CAD drawings. Recently, the industry has embraced many kinds of web-based technologies, but information still uses document-based model. It is believed that transition to model-based information can be done through web-based 3D user interface. Moreover, there is a need to easily model structures to be used in a web-based user interface [1]. From the introduction of color photography to full-motion video to computer-generated presentations with graphics and animations, visual technologies have enhanced the preparation of workforce specialists and technicians by bringing into classrooms and laboratories a breadth and depth of realism that has enhanced comprehension, increased learning performance, and reduced training time. The capabilities and possibilities for virtual reality (VR) technology may open doors to new vistas in industrial and technical instruction and learning, and the research that supports them.

Our study in this paper is to provide three-dimensional web-based technologies for managing, accessing, and viewing construction project information. The modeling of steel structures and construction equipment as objects for inclusion in construction-site world models was studied. Our work is to extend the power of VRML so that it is used not only for defining shape models, but also for creating structures for behavior.

\section{Virtual Reality And Simulated Training}

Virtual Reality (VR) refers to real-time systems modeled by computer graphics that allow user interaction and movements with three or more degrees of freedom [2,3]. VR combines many fields as computers, robotics, graphics, engineering and cognition. VR worlds are created by computer graphics techniques as $3 \mathrm{D}$ environments, where one or more users interact with virtual elements. VR is basically a way of simulating or replicating an environment and giving the user a sense of being there, taking control, and personally interacting with that environment with his/her own body [4]. As the technologies of virtual reality evolve, the applications of VR become literally unlimited. It is assumed that VR will reshape the interface between people and information technology by offering new ways for the communication of information, the visualization of processes, and the creative expression of ideas.

A virtual environment VE can represent any three-dimensional world that is either real or abstract. The virtual environment can take many forms and for example, it could be a realistic representation of a physical system. This includes real systems like buildings, landscapes, underwater shipwrecks, space crafts, archaeological excavation sites, human anatomy, sculptures, crime scene reconstructions, solar systems, and so on [5]. VE provides experiences that help people in understanding concepts as well as learning to perform specific tasks, where the task can be repeated as often as required in a safe environment. This is accomplished by Web3D open standards (VRML) which allow the delivery of interactive VEs through the Internet, reaching 
potentially large numbers of learners worldwide, at any time. Web3D VEs are also independent of platform and require only a plug-in Web browser.

Machining processes such as turning, milling, drilling and grinding can be visualized using VR. VR technology can also be used to evaluate the feasibility of a design, selection of process equipment and to allow a user to study the factors affecting the quality, machining time and costs. A VR system is essentially an interactive simulation that can represent a real or abstract system. The simulation is a representative computer based model, which provides appropriate data for visualization or representation of the system [6].

Graphically-realistic and interactive simulations bring the industrial environment directly to the user. They save costs compared to on-site visits. New techniques and complex procedures can be repeated until they are mastered. The use of virtual reality simulation in industrial training has expanded rapidly in the recent past, as development costs and computing power are no longer limiting factors to widespread adoption. They provide flexible and low cost training while expanding the reach to participants locally, nationally and internationally using shared 3D environments.

\section{VRML}

A common format used for displaying 3D models on desktop computers is the Virtual Reality Modeling Language (VRML) [7, 8], which is a scene description language for representing 3D interactive models on the web. It allows the viewer to examine the model at different angles and at different distances, all within a web browser. VRML worlds are extremely versatile in that they support interactivity, animation, user modification, and embedded hyperlinks to other Web documents. VRML models are displayed in freely available VRML plugins $[9,10,11,12]$ for Netscape or Internet Explorer.

Even though VRML files are smaller in size, when trying to realistically model an actual object or system, the files can quickly become complex. It may take time for model details to load up and render as the user moves about in a VRML world. As the bandwidth of the Internet grows, the amount of data that can be transmitted increases. This allows for more 3D-model visualization over the Internet that can be CPU intensive in addition to accommodating large file sizes.

VRML format is less complex when compared to other 3-D CAD programs and can easily be published on any web site. The actual VRML file is a textual description of the model that can be created using any text editor or word processor. VRML file names end with the extension .wrl and contains seven main types of components including a VRML header, prototypes, shapes, interpolators, sensors and scripts and routes.

The VRML prototype mechanism allows for the creation of application - specific geometric objects similar to the built-in primitives such as boxes, spheres, cones, and cylinders. Research at NIST [13, 14, 15] has developed a mapping between the CIM steel Integration Standard (CIS2) [16] and VRML. CIS2 is a logical product model [17] for describing steel structures and has been adopted by the American Institute of Steel Construction as their standard for electronic data interchange [18]. VRML prototypes have been developed that correspond to CIS2 entities such as parts (beams, columns, braces, clip angles, plates), bolts, holes, welds, and locations.

Various systems like Computer Aided Drafting (CAD) and Computer Aided Manufacturing (CAM) are widely integrated by the industries. VRML is used in the industry in Design Phase, Prototype Making, Prototype Simulation, Testing, Visualization, Manufacturing and every other possible aspect. For integration of the VRML in the Manufacturing, 3D format of the workstation is created. Various applications and simulations are made with the help of this 3D space.

For application of VRML in a manufacturing process, various manufacturing operations are needed to be identified. The manufacturing processes are then combined by the combination of these operations. The various manufacturing operations includes, loading and unloading of work piece, movement, storing, process like drilling, reaming, turning etc. and are dependent upon the design of the object to be created.

\section{VRML Limitations and Optimization}

VRML works well with both very powerful computers and very inexpensive machines. There is a trade off on image or simulation quality for improved performance and increased hardware performance [19]. VRML worlds should also scale with network performances, from 56K modems that are common today to multi gigabit connections that might become common in the future.

VRML has its own share of limitations. One of the limitations is that the amount of polygons in the VRML dictates the rendering time. The more polygons present, the more CPU time are needed to render the 3-D object. Simplicity is a design constraint, compromising details for faster rendering time. On the other hand, if the file size gets too large, a faster Internet connection speed will be needed. As mentioned previously, there are some tradeoffs in performance versus contents of a VRML file. Therefore, optimization is an essential part of creating VRML worlds. Given existing limitation on bandwidths and rendering speed, any world, which isn't 
carefully optimized, may be too slow to capture the audience's interest [20]. Content must be balanced with the performance requirements to keep everything running at interactive speeds.

Level of Detail (LOD) node can enclose different versions of a shape in varying levels of details. The LOD node is used to reduce the number of polygons visible at one time. For instance, if a level of detail node is used on a box object, when the user is far away from the object, the VRML browser would load up the model with less detail so that it does not need to render the extra details. This directly decreases the rendering time of the CPU, which then translates to faster movement in the VRML world. Other methods of optimization include, replacing complex surfaces with textures, inline code, collision nodes, and reducing the precision of floating point numbers to reduce file size and use of compression.

\section{Related Work}

University of Bath has developed a desktop virtual shop floor containing a 3-axis numerical control milling machine and a 5-axis robot for painting. The user can mount a work piece on the milling machine, choose a tool and perform direct machining operations, such as axial movements or predefined sequences [21]. Java, Virtual Reality Modeling Language (VRML) and the External Authoring Interface (EAI) have been employed to perform Numerical Control (NC) machining simulation in a networked VR environment [22]. The geometry of the work piece being cut will be updated dynamically.

A number of applications of VRML exist on the Web in various areas. One of them is a method for simulating basic manufacturing operations such as unload, load, process, move and store in a 3D virtual environment. The virtual environment provides a framework for representing a facility layout in $3 \mathrm{D}$ that consists of the static and dynamic behavior of the manufacturing system [23]. Another VR application is a virtual machining laboratory is for knowledge learning and skill training in an interactive environment. This virtual lab is specifically designed for helping students to virtually operate a lathe or set machining parameters and input CNC G-code programme to turn the work piece automatically [24, 25] have developed an integrated model of the spindle bearing and machine tool system, consisting of a rotating shaft, tool holder, angular contact ball bearings, housing, and the machine tool mounting. The model allows virtual cutting of a work material with the numerical model of the spindle during the design stage. Delmia's Virtual NC is also an interactive 3D simulation environment for visualizing and analyzing the functionality of an $\mathrm{NC}$ machine tool, its $\mathrm{CNC}$ controller and the material removal process [26].

\section{Implementation}

Virtual Reality Industry Training (VRIT) deals with Virtual industry training based on 3D models to set up an industry (a steel plant where steel beams are constructed using raw steel blocks). This project comprises of two parts. The first part shows a model of a factory and the second part displays the construction process of steel beams from raw steel blocks.

Components of a factory and the construction process of steel beams are modeled by VRML. The standard units needed to set up a factory are stored in a database. SQL Server 2005 is used as the backend tool. .NET platform is used to present the models to the users. The design of VRIL consists of various 3D models modeled in VRML as given below. Models designed for the construction of a factory.

a. Factory office

b. Crane

c. Drilling Machine

d. Lathe

e. Generator

f. Shed

g. Rest Room

h. Compound with gates and lights.

All these models are fabricated together to setup a factory. The information provided in the database is also simultaneously presented.

Similarly the 3D models of the construction of steel beams in various stages are also designed individually as given below and finally grouped together for the user's easy comprehension.

a. Collection of raw steel blocks

b. Preparing their edges by welding

c. Joining three pieces of steel to form a column

d. Drill holes in relevant areas in the steel column

e. Join the different columns to construct a steel beam.

These steps are also provided in a database maintained in SQL Server 2005. As the models are presented, the textual information is also displayed from the database.

The presentation of these constructs to the user is done through aspx web pages. 
i. The url of the website must be given in the address bar of the browser.

ii. http://localhost:1525/WebSite2/Default2.aspx

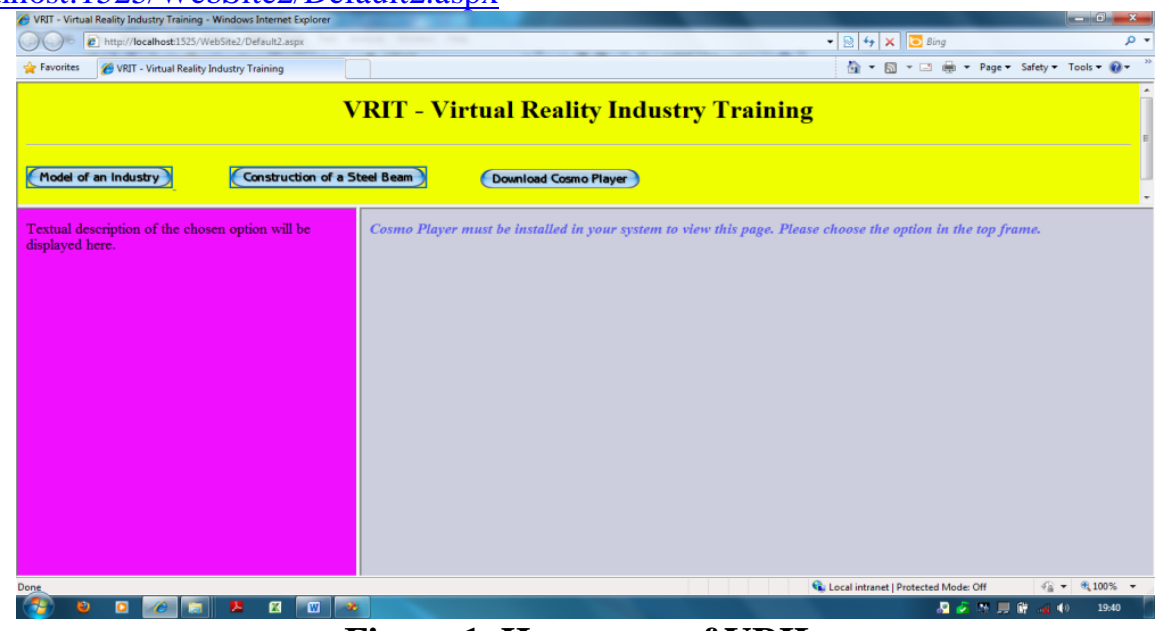

Figure 1. Homepage of VRIL

iii. The homepage is displayed with three frames as shown in fig 1 . The top frame lists the two parts of our project, the model of a factory and the construction process of steel beams. If Cosmo Player is not installed in the system on use, the Download Cosmo Player Button will link to the Cosmo Player home page for downloading. The software must be downloaded and installed in the system. The left frame is used to describe textually the chosen option of study. The right frame is to display the world of study.

iv. Click the option of study. The left frame displays the textual description of the world from a database and the model is displayed on the right frame. Fig 2 shows about the model of a factory.

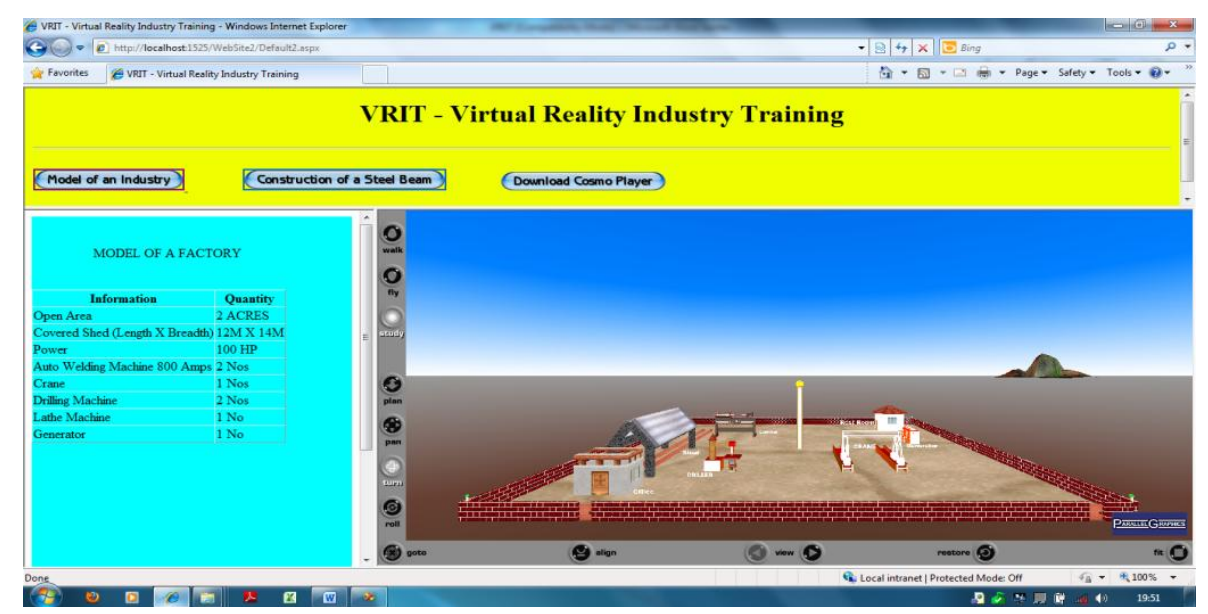

Figure 2. Model of a Factory

Fig 3 shows the construction process of a steel beam.

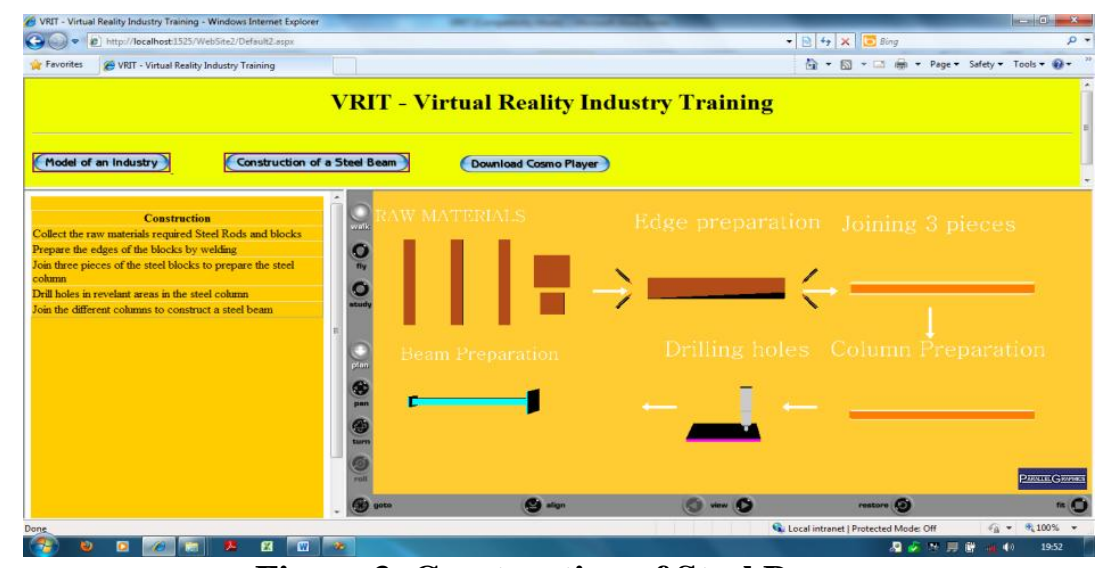

Figure 3. Construction of Steel Beam 


\section{Conclusion}

VR is used in engineering design and construction disciplines to develop and visualize project designs. Students and the trainees learn important construction planning concepts more quickly and are engaged in their learning experience. Most advanced visualization tools are needed to help educate future construction engineers.

The results of the experiments presented in this paper suggest that VR modelling with VRML helps to improve the industry training without taking the users to the training site. This is a low cost development tool for visualizing the virtual construction. This technology allows the trainees to explore a $3 \mathrm{D}$ visualization of the industry that has to be constructed, thus enabling them to understand more effectively through interactivity. The presented experimental scenarios can provide a rewarding learning experience that is otherwise difficult to obtain.

In the future more educational templates can be developed and multimedia content can be added. Human-computer interactions can be improved to make the system more interactive.

VRML Applications in Construction: Internet based Emerging Construction Technologies http://rebar.ecn.purdue.edu/ect/links/technologies/internet/vrml.aspx

[2]. Burdea, G. and Coiffet, P., Virtual Reality Technology (2nd ed. Wiley Interscience, 2003).

[3]. Vince, J. Virtual Reality Systems (Addison-Wesley, 1995).

[4]. Arts and Humanities Data Service (2002). Creating and using virtual reality: A guide for the arts and humanities. Retrieved February 21, 2004, from http://vads.ahds.ac.uk/guides/vr_guide

[5]. Beier, K. P. (2004). Virtual reality: A short introduction. Retrieved February 20, 2004, from http://wwwvrl.umich.edu/intro/index.html

[6]. Schofield, D. 1995. Virtual Reality Technology and its Application.

[7]. Ames A., Nadeau D., Moreland J., VRML 2.0 Sourcebook (2nd edition, John Wiley \& Sons, Inc., 1997).

[8]. Web 3D Repository, http://www.web3d.org/vrml/vrml.htm

[9]. Cosmo Player, http://www.ca.com/cosmo/

[10]. Cortona, http://www.parallelgraphics.com/products/cortona/

[11]. blaxxun Contact, http://www.blaxxun.com/

[12]. Pivoron Player, http://www.nexternet.com/

[13]. Visualization of Steel Structures from CIMsteel Integration Standards (CIS2) Files, http://cic.nist.gov/vrml/cis2.html

[14]. Lipman R., "Mapping VRML Prototypes to the CIMsteel Integration Standards", to appear.

[15]. Lipman R., Reed K., "Visualization of Structural Steel Product Models", Electronic Journal of Information Technology in Construction, to appear.

[16]. Crowley A., Watson A., "CIMsteel Integration Standards Release 2", Steel Construction Institute Publication P268, 2000, http://www.cis2.org/

[17]. Eastman, C., Building Product Models: Computer Environments Supporting Design and Construction (CRC Press, 1999).

[18]. AISCElectronicsDataInterchange,http://www.aisc.org/Content/NavigationMenu/Steel_Solutions_Center/Time,_Money_and_Manage ment/Electronic_Data_Interchange/Electronic_Data_Interchange.htm

[19]. Carey, R., Bell, G., The Annotated VRML 2.0 Reference Manual (First Edition, Addison Wesley, April 1997).

[20]. Hartman, J., Wendy, V., Cosmo Worlds: User's Guide (First Edition, Silicon Graphics, 1998).

[21]. Bayliss, G. M., Bowyer, A., Taylor, R.I. and Willis, P.J. Set-theoretic Solid Modelling Techniques and Applications. Virtual Manufacturing Proceedings, CSG 94, Winchester, UK, (1994), 353-365.

[22]. Qiu, Z. M., Chen, Y. P., Zhou, Z. D., Ong, S. K., Nee, A. Y. C.. Multi-User NC Machining Simulation Over the WWW. The International Journal of Advanced Manufacturing Technology, 2001 18: 1-6.

[23]. Chawla. R and Banerjee. A.. A Virtual Environment For Simulating Manufacturing Operations in 3D. Proceeding of the 2001 Winter Simulation Conference: 991-997.

[24]. Fang, X. D., Luo, S., Lee, N. J. and Jin, F. Virtual Machining Lab for Knowledge Learning and Skill Training. Computer Applications in Engineering Education, 1998. 6(2): 89-97.

[25]. Yuzhong Cao and Altintas, Y. Modeling of spindle-bearing and machine tool systems for virtual simulation of milling operations, International Journal of Machine Tools and Manufacture, 2007, 47(9): 1342-1350.

[26]. Delmia. 2001. Delmia Machining Solution. (online) http://www.delmia.com/ (20 April 2003).

[27]. Haslina Arshad, Zainal Rasyid Mahayuddin, Che Hassan Che Haron and Rosilah Hassan Flank Wear Simulation of a Virtual End Milling Process European Journal of Scientific Research ISSN 1450-216X Vol.24 No.1 (2008), pp.148-156 